\title{
Assessment of Dysfunctional Grief due to Death from COVID-19 in Peru: Adaptation and Validation of a Spanish Version of the Pandemic Grief Scale
}

\author{
Tomás Caycho-Rodríguez ${ }^{1}$ (D) - Lindsey W. Vilca ${ }^{2}$ - Andrea Vivanco-Vidal ${ }^{3}$. \\ Daniela Saroli-Araníbar ${ }^{3}$. Carlos Carbajal-León ${ }^{1}$ - Walter L. Arias Gallegos ${ }^{4}$. \\ Michael White ${ }^{5} \cdot$ Sherman A. Lee ${ }^{6}$
}

Accepted: 2 July 2021/Published online: 14 July 2021

(c) Associação Brasileira de Psicologia 2021

\begin{abstract}
This study evaluated the psychometric properties of the Pandemic Grief Scale (PGS), using Classical Test Theory (CTT) and Item Response Theory (IRT) methods, in a sample of 458 people who have suffered the loss of a loved one due to the COVID-19 pandemic. The Pandemic Grief Scale, Patient Health Questionnaire-2 (PHQ-2), the two-item Generalized Anxiety Disorder Scale (GAD-2), and a single item on suicidal ideation were used. The unidimensional model had good fit and reliability; furthermore, convergent validity was demonstrated based on the relationships between dysfunctional grief, anxiety symptoms, depression, and suicidal ideation. Additionally, a higher presence of dysfunctional grief is required to answer using the higher response categories. The evidence of validity and reliability of the PGS in its Spanish version, using traditional and modern methods, is confirmed in Peru.
\end{abstract}

Keywords COVID-19 · Grief · Reliability · Validity

Tomás Caycho-Rodríguez

tomas.caycho@upn.pe

1 Facultad de Ciencias de La Salud, Universidad Privada del Norte, Av. Alfredo Mendiola 6062,

Los Olivos, Lima, Perú

2 Departamento de Psicología, Universidad Peruana Unión, Lima, Perú

3 Facultad de Psicología, Universidad Peruana de Ciencias Aplicadas, Lima, Perú

4 Departamento de Psicología, Universidad Católica San Pablo, Arequipa, Perú

5 Dirección General de Investigación, Universidad Peruana Unión, Lima, Perú

6 Department of Psychology, Christopher Newport University, Newport News, VA, USA 


\section{Introduction}

On March 11, 2020, the World Health Organization (WHO) declared COVID19 a pandemic, following the occurrence of 118,000 diagnosed cases and 4291 deaths in 114 countries (Williamson et al., 2020). As of March 27, 2021 (the latest data available for this study), the number of diagnosed cases reached 126,476,562 worldwide, with 2,771,966 deaths due to COVID-19 (Coronavirus Resource Center, 2020). In Peru, there were 1,500,465 cases and 50,831 deaths from COVID-19 (Ministerio de Salud, 2021). This dire situation has affected almost every aspect of daily life, generating an increase in the rates of mental health disorders and substance use (Simon et al., 2020). However, despite evidence of actions to mitigate the psychosocial consequences of COVID-19 at a general level (Rauschenberg et al., 2021), the emotional needs of people who have lost a loved one to COVID-19 have not been fully met (Lee \& Neimeyer, 2020). This lack of attention is surprising, given that bereavement of this magnitude is considered a public health problem (Atwoli et al., 2017).

Grief is an inevitable and multidimensional human experience in the face of the death of a loved one, which is expressed in a set of affective, cognitive, behavioral, physical, and spiritual responses. For example, grief symptoms include, but are not limited to, longing, sadness, a sense of emptiness or absence of meaning in life, problems trusting others and accepting the loss, and anger associated with the loss and identity confusion (Gesi et al., 2020; Prigerson et al., 2009; Zhai \& $\mathrm{Du}, 2020)$. Although most bereaved individuals adapt to their loss, it is estimated that between 2 and $10 \%$ of the population experience difficulties in the grieving process, termed dysfunctional grief. Rates of dysfunctional grief may increase during the COVID-19 pandemic due to restrictions on people accompanying their family members before their death and other difficulties brought about by the adverse conditions of this infectious disease outbreak (Eisma \& Tamminga, 2020; Kokou-Kpolou et al., 2020). For example, interpersonal losses related to COVID19, along with other social changes, such as social distancing and restrictions on meetings, have changed the way individuals and families cope with bereavement (Eisma, \& Tamminga, 2020; Simon et al., 2020). In this sense, experiencing more than one death in a short time frame within families could generate an overload of mourning and grief that would interfere with an individual's ability to cope with such a situation; similarly, the high rate of disease spread and social restrictions do not allow visiting relatives in hospitals, assisting the dying in their last moments of life or performing funeral ceremonies, which can inhibit the expression of emotions and increase feelings of guilt (Hamid, \& Jahangir, 2020; KokouKpolou et al., 2020).

Due to the characteristics of COVID-19-associated losses, there is a suspected long-term increase in the prevalence of dysfunctional, persistent, and disabling grief (Eisma, \& Tamminga, 2020), which can last for months or even years after the death of a loved one (Bertuccio, \& Runion, 2020) and is even greater than grief from loss due to natural causes (Eisma et al., 2021). Risk factors for dysfunctional grief associated with COVID-19 loss include dependence on the 
person who died, premature, and unexpected circumstances of death, witnessing the moment of death and/or suffering, as well as having a previous mental illness (Johns et al., 2020). Similarly, others suggest that grief may be increased due to a lack of emotional support, stress due to financial hardship, concerns for one's own health and that of family members, and major disruptions of daily routines (Carr et al., 2020). In this sense, dysfunctional bereavement due to death related to COVID-19 appears to increase the risk of mental and physical health problems, increasing symptoms of anxiety, depression, post-traumatic stress, separation distress loneliness, suicidal ideation, fatigue, increased substance use, increased risk of heart attacks, and other diseases (Bertuccio \& Runion, 2020; Breen et al., 2021; Lenferink et al., 2020; Stroebe et al., 2007; Zisook et al., 2014). Also, these bereaved people may feel isolated and unable to access social support due to social distancing measures (Pearce et al., 2021). However, evidence on how the COVID-19 pandemic impacts the experience of dysfunctional grief and its prevalence is still limited, due, among other factors, to the absence of an instrument to measure its symptoms.

Seeking to fill this gap, Lee and Neimeyer (2020) developed and evaluated the psychometric evidence for the Pandemic Grief Scale (PGS) as a brief measure of dysfunctional grief due to the death of a loved one from COVID-19. The PGS is comprised of five items measuring five grief symptoms associated with distress and disability. The psychometric study of the original English version of the PGS (Lee \& Neimeyer, 2020) was conducted with the participation of 831 adults who lost someone close to them due to COVID-19, demonstrating that the five items cluster into a single dimension (from a principal components analysis and confirmatory factor analysis), with adequate reliability (Cronbach's alpha $=0.86$ ) and showing significant and strong correlations with suicidal ideation, anxiety, depression, and substance use coping. In addition, the PGS measured dysfunctional grief related to COVID-19 in the same way across different age groups (18 to 29 years and 30 years and older), sex (male and female), and race (White and non-White). It also discriminates adequately between people with and without dysfunctional grief at a cut-off score of 7, with $87 \%$ sensitivity and $71 \%$ specificity.

To date, only two additional studies have evaluated the psychometric properties of the PGS in other languages, namely, Turkish (Evren et al., 2021) and Polish (Skalski et al., 2021). The results of the Turkish study showed that the one-factor structure was satisfactory with adequate reliability (Cronbach's alpha $=0.77$; composite reliability $=.90$ ); moreover, the mean score of the PGS showed positive correlations with measures of depression, social and work adjustment, suicidal ideation, and coping with substance use. Similarly, the PGS allows for discriminating between people experiencing dysfunctional grief or not, from a cut-off score greater than or equal to 3 , with $89 \%$ sensitivity and $72 \%$ specificity. The study in Poland revealed that the PGS maintains a unifactorial structure with satisfactory reliability (Cronbach's alpha=0.89). In addition, the PGS showed evidence of convergent validity, due to its associations with a measure of complicated grief, depression, and resilience. Also, the absence of a relationship between the PGS and health behaviors provided evidence of discriminant validity for the scale. 
Previous psychometric studies were conducted on the basis of Classical Test Theory (CTT), but more and more studies are now turning to Item Response Theory (IRT) to provide more detailed information about the contribution of each item to the reliability and validity of an instrument. However, to date, no study has used both CTT and IRT to assess the PGS psychometrically. Because CTT-based models analyze scales as a whole, they only provide information about the correlation between item responses, and do not consider how an individual or group will respond to a given item (Hambleton et al., 1991). Furthermore, CTT models assume that all items provide the same information about the latent variable (in this case, dysfunctional grief) (Petrillo et al., 2015). On the other hand, IRT models can provide information about the difficulty and discrimination ability of each item, regardless of the sample (Crocker, \& Algina, 1986; Lord, 1982). Also, IRT provides information about the measurement of a latent trait at the item and test level, rather than providing a single estimate of reliability, which would help identify those items that contribute most to measurement accuracy (Cooper \& Petrides, 2010). Based on these reasons, we believe that an IRT approach could provide more complete psychometric information than using CTT alone (Nicholson et al., 2013). Furthermore, IRT has been proposed as a recommended means of improving measurement in psychiatry (Adler, \& Brodin, 2011).

Although the findings reported with the English and Turkish versions demonstrate that the PGS is a reliable and valid instrument for measuring dysfunctional grief related to death related to COVID-19, to date, there is no Spanish version of the scale. In addition, as mentioned above, the psychometric properties of the PGS have been evaluated with the CTT, but not by means of an IRT analysis. There are also no studies on the prevalence of COVID-19 pandemic grief or its risk factors in Peruvian culture. Therefore, to address these shortcomings, an empirical study was designed (Ato et al., 2013) to evaluate the psychometric properties of the PGS using both CTT and IRT methods. Specifically, evidence of validity based on internal structure, evidence of convergent validity with measures of anxiety, depression, and suicidal ideation, internal consistency reliability, as well as the characteristics and performance of the PGS items based on IRT analysis, were evaluated.

Based on previous findings, we expected that the five PGS items would cluster into a single latent factor and that the model we test would demonstrate adequate evidence of reliability with our sample of bereaved adults in Peru (Evren et al., 2021; Lee \& Neimeyer, 2020). Our adapted version of the PGS was also expected to correlate moderately with symptoms of anxiety and depression because they are related, but distinct constructs from grief (Breen et al., 2021; Evren et al., 2021; Lee \& Neimeyer, 2020). Similarly, a moderate positive correlation between the PGS and suicidal ideation was expected to be found because those suffering from acute grief tend to also have thoughts of death and suicide (Evren et al., 2021; Lee \& Neimeyer, 2020). Finally, although there are no previous studies of the PGS based on IRT models, it would be expected that its items present adequate parameters of difficulty and discrimination.

Therefore, findings based on the CTT would corroborate previous psychometric evidence on the PGS, whereas findings based on the IRT would provide 
a better understanding of the psychometric properties of the scale. It is also important to consider the cross-cultural utility of the instruments for the detection of dysfunctional pandemic grief. In this regard, social norms for expressing dysfunctional grief may differ across cultural contexts, which may lead to differences in the occurrence of its symptoms (Ito et al., 2012). Bereavement develops in a specific family and community context through social interaction; therefore, grief-related practices will differ according to the individual's cultural background (Hardy-Bougere, 2008). Thus, the duration, frequency, and intensity of grief can be different according to individual, family, and cultural beliefs (Rosenblatt, 2001). For example, in Latino culture, open expressions of grief and crying during bereavement are considered healthy and encouraged (HardyBougere, 2008; Parry \& Ryan, 1996), whereas in the USA, the grieving process is considered a private matter that may become uncomfortable for others (Powell, \& Matthys, 2013). Thus, because previous psychometric findings were derived from North American and European cultures, the study of the PGS in Latin American cultures is important (Fujisawa et al., 2010).

\section{Method}

\section{Participants}

A total of 458 people participated in the study. The inclusion criteria were as follows: Peruvian people, over 18 years of age, who have lost a loved one to COVID-19 and are able to respond to online surveys. Participants were selected by non-probability snowball sampling (Atkinson \& Flint, 2004). Once an individual was identified as meeting the established inclusion criteria, he or she was asked to share the online survey with others who have experienced bereavement related to COVID-19. It is suggested that, in online studies, snowball sampling facilitates contacting participants from diverse locations and leads to a higher response rate compared to other types of sampling (Baltar \& Brunet, 2012). The number of participants was determined with the Soper's software (2021) for structural equation modeling (SEM) studies, based on the number of observed and latent variables (5 and 1 respectively), the anticipated effect size (lambda $=0.1)$, the desired probability $(0.05)$, and the statistical power $(0.95)$.

Participants ranged in age from 18 to 58 years old, with an average age of 30.98 years old $(\mathrm{SD}=9.91)$, where 141 were male $(30.79 \%)$ and 317 were female (69.21\%). $42.23 \%$ indicated having had a positive diagnosis for COVID19. The majority of participants reported losing extended family members $(n=215 ; 46.94 \%)$, followed by immediate family members $(n=104 ; 22.71 \%)$, friends $(n=100 ; 21.83 \%)$, partners $(n=30 ; 6.55 \%)$, and others $(n=9 ; 1.97 \%)$ to the COVID-19 pandemic. Also, 58.92\% had been grieving for 3 to 6 months, $25.76 \%$ for less than 3 months, and $15.32 \%$ for more than 6 months. Finally, only $15.12 \%$ reported seeking professional support to manage their grief over their loss. 


\section{Instruments}

Sociodemographic Information A survey was prepared in which the participants provided information about their age, sex, diagnosis of COVID-19, degree of relationship with the deceased, time since the death occurred, and request for professional support for the management of grief due to the loss.

Pandemic Grief due to COVID-19 The Pandemic Grief Scale (PGS; Lee \& Neimeyer, 2020) assesses dysfunctional grief due to death caused by COVID-19. The PGS is comprised of 5 items assessing grief symptoms associated with distress and disability occurring in the past 2 weeks and has four response options, ranging from $0=$ "not at all" to $3=$ "almost every day." The total scale score is obtained by summing the scores for each item, where a higher score would indicate a higher frequency of dysfunctional bereavement symptoms. Likewise, a total score equal to or greater than 7 would indicate the probable presence of dysfunctional grief due to a death related to COVID-19, which would suggest a need for further assessment or treatment. The PGS was translated into Spanish according to recommendations for cross-cultural adaptation of self-report measures (Beaton et al., 2000):

1. First, two bilingual native speakers of Spanish (the first was a mental health professional with knowledge of the subject matter and the second was a professional translator without knowledge of the subject matter) made two independent translations from English to Spanish. Based on the comparison of the two translations, an initial Spanish version of the PGS was developed.

2.Second, the initial Spanish version was translated back into English by two independent translators whose native language was English, but who were fluent in Spanish.

3.Third, the four translators mentioned above, together with two subject matter experts who were members of the research team, evaluated all translated versions and the original version, from which a draft version of the PGS in Spanish was developed.

4.Fourth, the preliminary version of the PGS was administered to 10 adults to assess its comprehensibility and readability. The experts together with the translators reviewed the results of the initial application to modify the PGS items if necessary. The respondents did not suggest any modifications, which allowed us to have a final version of the PGS in Spanish.

Table 1 presents the original version and the final Spanish translated version of the PGS.

Depressive Symptoms Depressive symptoms were assessed with the Patient Health Questionnaire (PHQ-2, Kroenke et al., 2003) consisting of two items that assess important symptoms of a clinical diagnosis of depression ("feeling discouraged, depressed, or hopeless" and "little interest or pleasure in doing things"). Each item is scored on a Likert scale with 4 response options $(0=$ not at all to $3=$ almost every day), where the total score ranges from 0 to 6 . It has been suggested that a 
Table 1 Original English version and Spanish translation of the PGS

\begin{tabular}{|c|c|}
\hline Items from the original English version & Translation of the items in the Spanish version \\
\hline $\begin{array}{l}\text { Over the last } 2 \text { weeks, how often have you } \\
\text { experienced the following thoughts, feelings, or } \\
\text { behaviors related to your loss? }\end{array}$ & $\begin{array}{l}\text { Durante las últimas } 2 \text { semanas, ¿con qué frecuencia } \\
\text { ha experimentado los siguientes pensamientos, } \\
\text { sentimientos o comportamientos relacionados con } \\
\text { su pérdida? }\end{array}$ \\
\hline $\begin{array}{l}\text { Item 1: I wished to die in order to } \\
\text { deceased }\end{array}$ & tar con la persona que \\
\hline $\begin{array}{l}\text { Item 2: experienced confusion over my role in life } \\
\text { or felt like my identity was diminished because } \\
\text { of the loss }\end{array}$ & $\begin{array}{l}\text { Item 2: Experimenté confusión sobre mi papel en } \\
\text { la vida o sentí que mi identidad había cambiado } \\
\text { debido a la pérdida }\end{array}$ \\
\hline $\begin{array}{l}\text { seemed to matter much to me } \\
\text { is loss }\end{array}$ & $\begin{array}{l}\text { Nada parecía importarme debido a esta } \\
\text { a }\end{array}$ \\
\hline $\begin{array}{l}\text { t difficult to have positive me } \\
\text { ceased }\end{array}$ & $\begin{array}{l}\text { cil tener recuerdos positivos } \\
\text { la }\end{array}$ \\
\hline $\begin{array}{l}\text { Item 5: I believed that without the deceased, life } \\
\text { was either meaningless, empty, or could not go } \\
\text { on }\end{array}$ & $\begin{array}{l}\text { Ítem 5: Creía que, sin la persona fallecida, la } \\
\text { vida carecía de sentido, estaba vacía o no podía } \\
\text { continuar }\end{array}$ \\
\hline
\end{tabular}

This translation followed a process of forward and back translation with a focus group to review the translated Spanish version

cut-off score greater than or equal to 3 is optimal for identifying those with major depressive disorder (Löwe et al., 2005). The PHQ-2 is an instrument that has been shown to be valid and reliable internationally (El-Den et al., 2018). In this study, we used the Spanish version which has demonstrated adequate reliability and utility in instrumental research on other mental health indicators during the COVID-19 pandemic in Peru (Caycho-Rodriguez et al., 2020; Caycho-Rodriguez et al., 2021a; Caycho-Rodriguez et al., 2021b). In the present study, the reliability of the PHQ-2 was adequate $(\alpha=0.94 ; \omega=0.91)$.

Generalized Anxiety The two-item Generalized Anxiety Disorder Scale (GAD2 ; Kroenke et al., 2007) was used to assess the frequency with which an individual has experienced anxiety symptoms during the last 2 weeks. It consists of two items ("feeling nervous, anxious, or on edge" and "unable to stop worrying or unable to control worry") that are scored on a 4-point Likert-type scale $(0=$ not at all to $3=$ almost every day) with a total score ranging from 0 to 6 , with higher scores indicating a higher frequency of severe anxiety symptoms. As with the PHQ-2, a score of 3 is an acceptable cut-off point for identifying individuals with, in this case, generalized anxiety disorders. The GAD-2 has been shown to have internationally acceptable psychometric properties for identifying generalized anxiety disorders. In this study, we used the Spanish version which has been used in recent research on mental health indicators in the Peruvian population during the COVID-19 pandemic (Caycho-Rodríguez, et al., 2021a, 2021b, 2021c). The reliability of the GAD-2 in this study was adequate ( $\alpha=0.91 ; \omega=0.88)$. 
Suicidal Ideation This was measured from a single item used in a previous study (Lee \& Neimeyer, 2020): "I wish I was dead so I wouldn't have to deal with this loss." This item had four Likert-type response options $(0=$ not at all to $3=$ almost every day). The translation process for this item was the same as that used for the PGS.

\section{Procedure}

The study was conducted between January 25 and February 26, 2021, during the state of emergency in Peru due to the COVID-19 pandemic. During this period, a focused mandatory social isolation edict was in effect, dividing the departments of Peru according to alert levels (moderate, high, very high, and extreme). In this regard, the capacity for public attention and mobilization of citizens varied according to the level of alert by department. Likewise, meetings and gatherings of people continued to be prohibited, and parades, patron saint festivities, and civil activities were suspended, as well as all types of meetings, social, political, cultural, or other events that involve crowds of people and social gatherings in homes and family visits. An online survey was created on the Google Forms platform, which was shared via email, WhatsApp, and social networks such as Facebook and Instagram. All participants gave informed consent. Only individuals who gave consent in the online survey could answer the questions in the questionnaire. The introduction to the form assured that personal information would remain confidential and would not be disclosed to third parties, as well as the possibility of withdrawing from the study at any time without needing to justify their decision.

All procedures were in accordance with the ethical principles of the Declaration of Helsinki published in 1975 and revised in 2000. In addition, the study obtained the approval of the ethics committee of the Universidad Privada del Norte (registration number: 20203001).

\section{Data analysis}

First, descriptive statistics were calculated for the PGS items (i.e., means, standard deviations, skewness, and kurtosis). For the confirmatory factor analysis (CFA), the diagonally weighted least squares with mean and variance corrected (WLSMV) estimator was used due to the ordinal nature of the items (Brown, 2015). Model fit was assessed based on the chi-square test $\left(\chi^{2}\right)$, the root mean square error of approximation (RMSEA), and the standardized root mean square residuals (SRMR), where values less than 0.05 indicate good fit, and between 0.05 and 0.08 is considered an acceptable fit (Kline, 2015). In addition, the Confirmatory Fit Index (CFI) and Tucker-Lewis Index (TLI) were used, where values greater than 0.95 indicate good fit and greater than 0.90 an acceptable fit (Schumacker \& Lomax, 2015). To assess reliability by the internal consistency method, Cronbach's alpha coefficient ( $\alpha$; Cronbach, 1951) and the omega coefficient (McDonald, 1999) were used, where values of $\alpha$ and $\omega>0.80$ are adequate $(\omega$; Raykov \& Hancock, 2005). Factor loadings $(\lambda)$ greater than 0.50 were considered 
adequate (Dominguez-Lara, 2018). Convergent internal validity was estimated from the calculation of the average variance extracted (AVE), where values greater than 0.50 are adequate (Fornell \& Larcker, 1981). The assessment of evidence for convergent validity of the PGS was conducted using another CFA specifying a model with four two related factors (dysfunctional grief from COVID-19, anxiety, depression, and suicidal ideation). The fit of this model was assessed on the basis of the aforementioned indices.

For the evaluation of the PGS based on Item Response Theory (IRT), a Graded Response Model (GRM, Samejima, 1997) was used, which is an extension of the 2-parameter logistic model (2-PLM) for ordered polytomous items (Hambleton, et al., 2010). For each of the PGS items, two types of parameters were estimated as follows: discrimination $(a)$ and difficulty $(b)$. The $a$ parameter determines the slope at which item responses change as a function of the level in the latent trait and the $b$ parameters determine the amount of the latent trait that a response alternative needs in order to have a higher probability of being chosen. Because each item has four response categories, there are three estimates of $b$, one per threshold. The estimates for these three thresholds indicate the level of the latent variable at which an individual has a $50 \%$ chance of scoring at or above a particular response category. Item Information Curves (IIC) and the Test Information Curve (TIC) were also calculated.

All statistical analyses were performed in the RStudio environment (RStudio Team, 2018) for R (R Core Team, 2019), using the "lavaan" package (Rosseel, 2012) for the CFA and the "ltm" package for the GRM (Rizopoulos, 2006).

\section{Results}

\section{Descriptive Analysis}

Table 2 shows that item 2 (I experienced confusion about my role in life or felt that my identity had changed due to the loss) has the highest mean in the sample $(M=1.60)$, while item 1 (I wanted to die to be with the person who died) has the lowest mean $(M=1.34)$. Furthermore, it can be seen in the polychoric correlation matrix that all the items have a high correlation coefficient. Regarding the skewness and kurtosis indices, it can be seen that items 2, 3, 4, and 5 present adequate indices ( $\mathrm{g} 1$ and $\mathrm{g} 2< \pm 2$ ), according to the criteria of Finney and DiStefano (2006). However, item 1 presents a markedly asymmetric response pattern with a high concentration of scores in the first response categories $(\mathrm{g} 1=2.32$; $\mathrm{g} 2=4.52)$. Likewise, all the items showed a floor effect, with more than $15 \%$ of the participants obtaining the minimum score (Terwee et al., 2007). There was no ceiling effect in any of the items.

An exploratory descriptive analysis of the levels of dysfunctional grief related to COVID-19, generalized anxiety and depression was performed. Results indicated that $39.3 \%$ of participants reported the presence of dysfunctional grief due to the loss of a loved one related to COVID-19. 


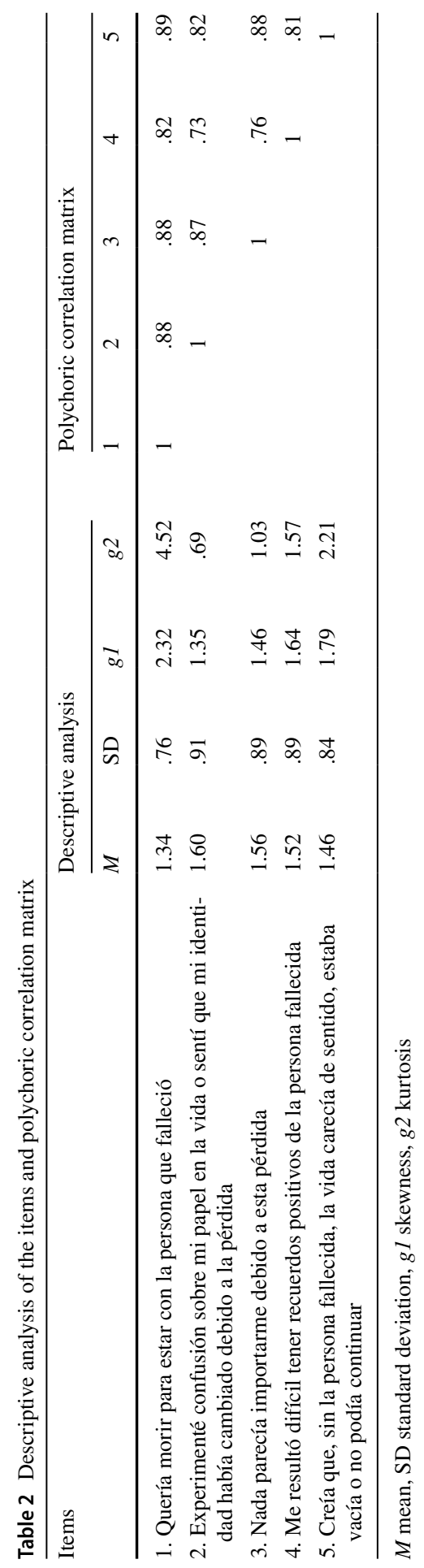


Fig. 1 The factor loadings of each of the PGS items

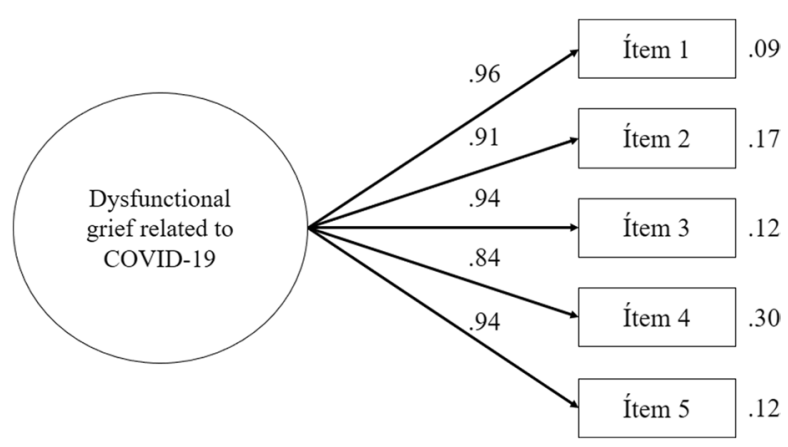

\section{Validity Based on Internal Structure and Reliability}

The unidimensional model presents adequate fit indices in the total sample of participants $\left(\chi^{2}=23.64 ; \mathrm{df}=5 ; p=0.000 ; \mathrm{RMSEA}=0.090 \quad\right.$ [CI90\% $0.056-0.128$; $\mathrm{SRMR}=0.017 ; \mathrm{CFI}=0.99$; TLI=0.99). In addition, it can be seen that the factor loadings of each of the PGS items are significant and greater than 0.50 (DominguezLara, 2018), as shown in Fig. 1. The AVE value was 0.85. Finally, the scale evidences adequate reliability indices $(\alpha=0.96 ; \omega=0.93)$.

\section{Item Response Theory Model: Graded Response Model}

The results found in the confirmatory factor analysis (CFA) allow the two main assumptions to be met the existence of unidimensionality and consequently local independence. Therefore, a Graded Response Model (GRM) was used for ordered polytomous items. Table 3 shows that items 1,2, 3, and 5 present discrimination parameters above the value of 1 , generally considered good discrimination (Hambleton, et al., 2010). However, item 4 does not show adequate discrimination indices $(a=<1)$. Regarding the difficulty parameters, all threshold estimators increased monotonically.

Figure 2 shows the IIC and the TIC. The IIC shows that item 1 is the most accurate item of the scale for assessing the latent trait. In addition, the TIC shows that the test is more reliable (accurate) in the range of the scale between 1.2 and 2.5.

Table 3 Discrimination and difficulty parameters for each item in the scale

\begin{tabular}{llllll}
\hline Model & Item & $\mathrm{a}$ & $b_{1}$ & $b_{2}$ & $\mathrm{~b}_{3}$ \\
\hline Unidimensional & Item 1 & 4.66 & 1.53 & 1.77 & 2.00 \\
& Item 2 & 1.40 & -.16 & .63 & 1.41 \\
& Item 3 & 1.22 & -.01 & .89 & 1.79 \\
& Item 4 & .98 & .16 & 1.29 & 2.41 \\
& Item 5 & 1.2 & .50 & 1.41 & 2.33 \\
\hline
\end{tabular}

$a$ discrimination parameters, $b$ difficulty parameters 


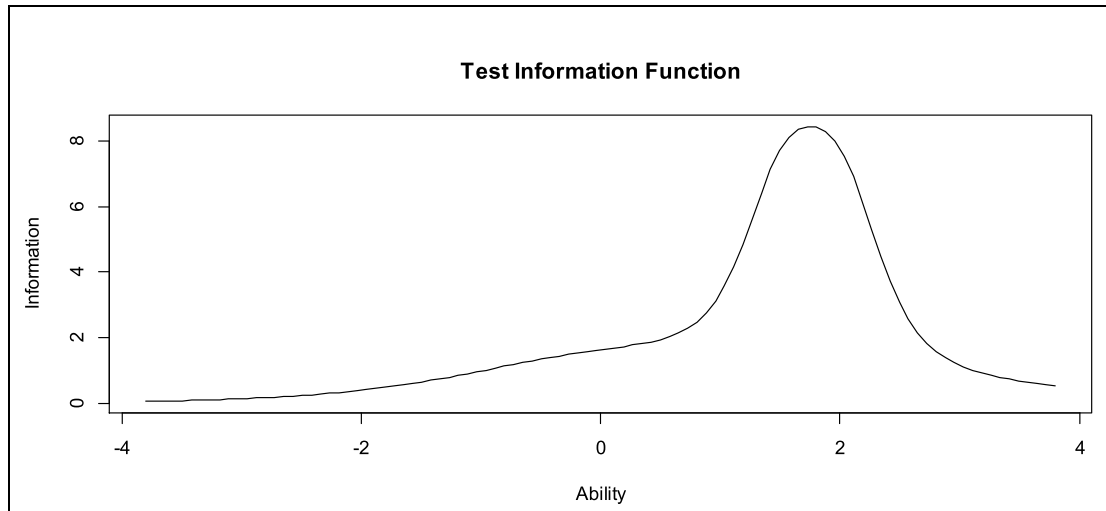

Tests Information Curves (TIC)

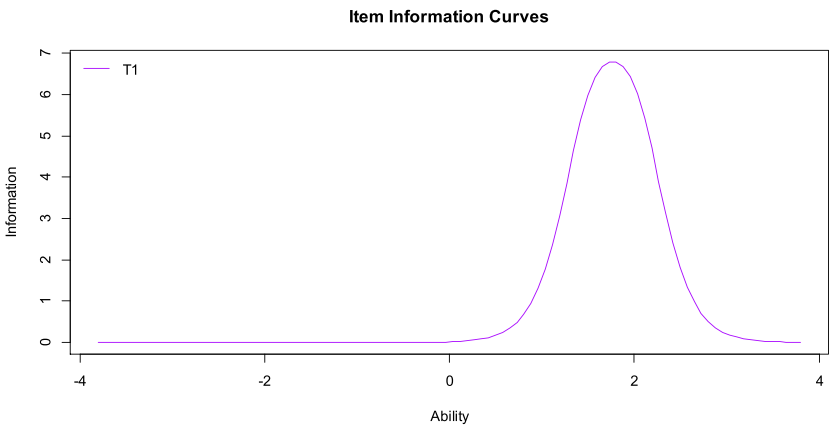

Item Information Curves (IIC) of item 1

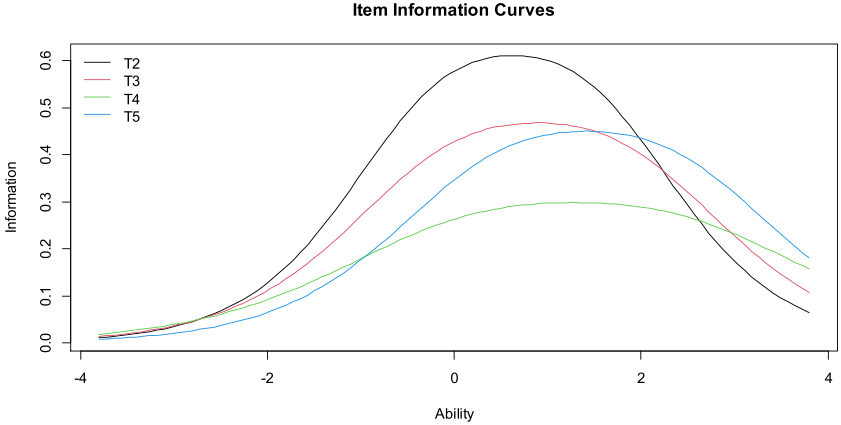

Item Information Curves (IIC) of item 2 to 5

Fig. 2 Item and test information curves for the scale 


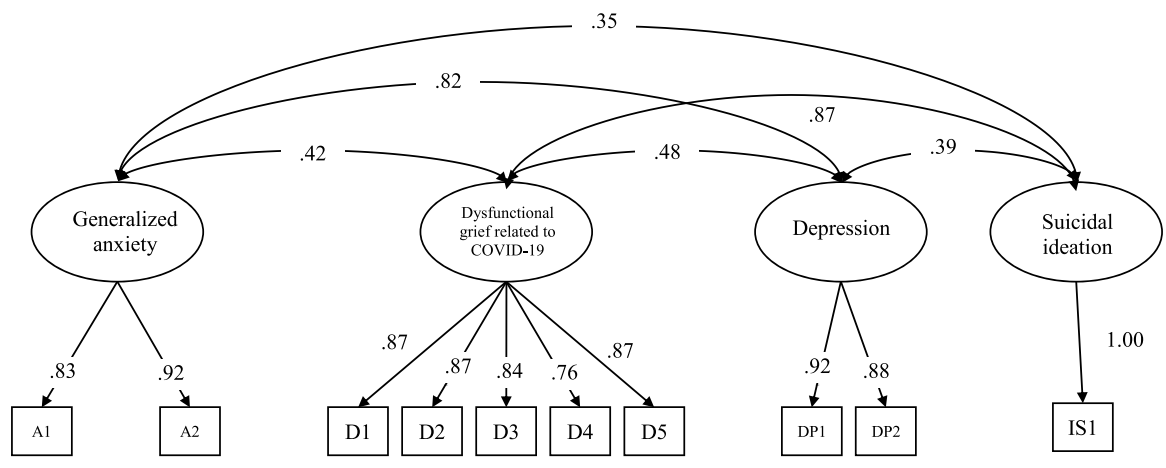

Fig. 3 Models of the scale's relationships with other constructs

\section{Convergent Validity}

Taking into account the literature review, an SEM model was proposed to evaluate the latent relationship between dysfunctional grief due to COVID-19, anxiety, depression, and suicidal ideation. The structural model presents adequate fit indices $\left(\chi^{2}=797.846 ; \mathrm{df}=45 ; p=0.000 ; \mathrm{RMSEA}=0.042\right.$ (CI90\%: 0.023-0.060; $\mathrm{CFI}=0.97$; $\mathrm{TLI}=0.95)$ and the measurement models are adequately represented by their items. Figure 3 shows that dysfunctional grief associated with COVID-19 is positively related to anxiety $(r=0.42 ; p<0.01)$, depression $(r=0.48 ; p<0.01)$, and suicidal ideation $(r=0.87 ; p<0.01)$. The strengths of the correlations between dysfunctional grief associated with COVID-19, anxiety, and depression are considered medium, while the strength of the correlation between dysfunctional grief associated with COVID-19 and suicidal ideation is large (Cohen, 1992). Taking these results into account, it can be concluded that the PGS demonstrate strong evidence of convergent validity.

\section{Discussion}

At the time of this study, the COVID-19 pandemic continues to be a major public health problem, with thousands of fatalities worldwide and significant impacts on physical and mental health (Satici et al., 2020). Therefore, it is crucially important to have assessment tools to investigate the effects of COVID-19 on people's mental health and to favor the development and implementation of intervention programs. That is why the main objective of this study was to evaluate the psychometric properties of the Spanish version of the PGS in people who have suffered the loss of a loved one due to COVID-19, using classical psychometric methods, such as CFA, and modern ones, such as the IRT.

First, the presence of a floor effect in the PGS items is observed, suggesting the presence of a restricted range of responses that could affect the variance of the items 
(Terwee et al., 2007). However, this is to be expected in the general population, where clinical variables are less prevalent (Chávez-Flores et al., 2018). Second, the results of the CFA provide evidence that confirms the unidimensional structure of the PGS in Spanish, with items that present high factor loadings even above what is recommended (Dominguez-Lara, 2018). These results are similar to what has been reported in the United States (Lee \& Neimeyer, 2020), Turkey (Evren et al., 2021), and Poland (Skalski et al., 2021), where the single factor structure of the PGS seems to be consistent across different cultures. However, the RMSEA value was higher than the recommended cut-off points (Kline, 2015; Schumacker \& Lomax, 2015). This is to be expected, because the RMSEA performs poorly in factor models with few degrees of freedom, as in the case of the PGS (Kenny et al., 2015; Taasoobshirazi \& Wang, 2016). However, the validation study of the Polish version of the PGS indicated the presence of a correlation between errors on items 2 and 3 (Skalski et al., 2021). The presence of a correlation between errors could increase the fit indices and mask a misspecified model (Dominguez-Lara, 2019). In addition, it could produce an over- or underestimation of reliability, caused by the participation of variance not associated with the construct, generating a bias in the interpretation of the accuracy of the PGS in Spanish (Yang, \& Green, 2010). On the other hand, although the factorial structure was the same in the USA, Turkey, Poland, and Peru, additional studies are needed before it is safe to assume the comparability of measurements between different countries, since the cultural context of each country can influence the expression of emotions ( $\mathrm{Li}$ et al., 2012). Thus, it is still necessary to demonstrate the invariance of the cross-cultural measurement using the PGS, which would allow for studying how members of different countries attribute similar meanings to the items of a measurement instrument, so that individuals with the same level in a trait will give the same answers to the items, regardless of the country in which they live (Milfont \& Fischer, 2010).

Similarly, the results about the internal consistency and reliability of the PGS in Spanish indicated adequate values for the alpha and omega coefficients. These findings are comparable to the alpha coefficients of the original scale in English (Lee \& Neimeyer, 2020) and higher than those reported in the Turkish version (Evren et al., 2021). The additional calculation of the omega coefficient was performed as it is considered a better alternative than Cronbach's alpha (McNeish, 2018). Still, for the calculation of the alpha coefficient, the PGS items were considered continuous and not ordinal variables, which would be more appropriate when estimating the reliability of scores derived from a simple unweighted sum of item scores (Revelle and Condon, 2019).

Analysis of the discrimination and difficulty parameters allows us to pinpoint the functioning of the PGS items in more detail. Item 1 (I wanted to die to be with the person who died) has the highest discrimination value, indicating that it can generate widely differing responses (from not at all to almost every day) in individuals with different levels of dysfunctional grief. People's responses to the first item of the PGS would provide more information about dysfunctional grief because it refers to a desire for death, which is a symptom of persistent complex grief disorder (Boelen, \& Smid, 2017; Lenferink, \& Eisma, 2018). Thus, people with critical difficulties in overcoming grief will find it easy to respond higher to this item with respect to those 
without this difficulty. Moreover, it is considered to be the most important item and the one that provides the most robustness to the PGS. Likewise, during the COVID19 pandemic, suicidal ideation has a prevalence that varies between 10 and $60 \%$ depending on age, the racial group to which they belong, type of work performed by individuals, suspected or confirmed COVID-19 infection, or presence of mental disorders (Czeisler et al., 2020; Shi et al., 2021; Tasnim et al., 2020). Similar results have been observed in previous viral diseases (Leaune et al., 2020). The other items also present adequate discrimination parameters, demonstrating that the difficulty required to answer the items is always ascending, which is ideal in an instrument that measures psychological distress. In other words, a greater presence of the latent trait is required to answer the higher response categories.

In addition, the IIC and TIC allow us to better understand the overall performance of the test based on the individual performance of the items with respect to different levels of trait in the participants. The high value in the discrimination parameter of the first item makes it a major contributor to the amount of information that the PGS can obtain between 1 and 3 logits of ability, i.e., the responses on this item could provide the test with the possibility of being able to discern between those who have critical dysfunctional grief from those who have severe dysfunctional grief. The individual behavior of the rest of the items complements the functioning of the first one, since they allow for receiving information from people with a less marked dysfunctional grief and/or with an absence of it ( -0.5 to 1.5 logits). However, upon observing the TIC, it is evident that the core of the PGS measurement falls heavily on item 1 , and that in the event of problems in answering it or an empty/missing response, the interpretation of the instrument with the remaining 4 items would be unfeasible. Thus, and in consideration of the above, the PGS presents important and essential properties for a screening instrument aimed at the evaluation of a clinical construct which is highly relevant in the current situation, and can be used for the evaluation of a population that has suffered the loss of a loved one due to COVID-19.

The PGS presented evidence of convergent validity through the positive correlations between dysfunctional grief associated with COVID-19 and symptoms of anxiety, depression, and suicidal ideation, as demonstrated by other studies (Evren et al., 2021; Lee \& Neimeyer, 2020). In this sense, the relationships between dysfunctional grief and depressive symptoms can be explained by the restrictions of social interaction due to the pandemic, which have all but eliminated social support and the made performing funeral ceremonies impossible or highly limited, which in turn has caused people to experience their grief in isolation (Mortazavi et al., 2020). Furthermore, the loss of a loved one can also generate anxiety that, in turn, lead the mourner to experience a more prolonged grief, especially when a loss has been very difficult (Shear, \& Skritskaya, 2012; Zisook et al., 1990). Although bereavement symptoms often co-occur with symptoms of depression and anxiety (KokouKpolou et al., 2020), the moderate correlations between them reported in the present study demonstrate that these three symptom clusters represent different but related constructs (Boelen, \& van den Bout, 2005; Dillen et al., 2009; Lichtenthal et al., 2004). Thus, symptoms of dysfunctional grief related to COVID-19 may be similar to symptoms of anxiety or depression, but differ in that they are direct reactions 
to loss (Bertuccio \& Runion, 2020). Therefore, evidence suggests that treatments that reduce symptoms of anxiety and depression may be effective for better bereavement management (Marques et al., 2013). Similarly, the experience of bereavement is associated with an increased risk of suicidal ideation (Molina et al., 2019). This finding was consistent with previous studies that also reported positive correlations between persistent grief symptoms and suicidal ideation before the pandemic ( $r=0.61$; Lee, 2015) as well as during ( $r=0.65$; Lee, \& Neimeyer, 2020); however, the correlation in this current study is stronger $(r=0.87)$. Although the correlation between the two is high, it is not high enough to be considered redundant $(r \geq 0.90$; Kline, 2015). This may be due to the inclusion in the PGS of items assessing alterations in personal identity which, due to its existential nature, is closely associated with suicidal ideation (Hill et al., 2019). On the other hand, from the interpersonal theory of suicide (Van Orden et al., 2010), it is proposed that the interaction between the belief of being a burden and that other people would benefit in some way from our death (perceived burden), as well as the feeling of loneliness, social isolation, and low social support (frustrated belonging), contributes very strongly to the presence of suicidal ideation. Additionally, it was found that $39.3 \%$ of the participants presented dysfunctional grief due to the loss of a loved one due to COVID-19. This percentage is lower than that reported in the USA population (between 66.1 and 66.4\%; Breen et al, 2021; Lee \& Neimeyer, 2020), where the impact of the pandemic on the mental health of the population has been greater (Fitzpatrick et al., 2020; Twenge, \& Joiner, 2020), because it has been the country with the highest number of reported cases $(30,707,536$ people infected) and deaths $(2,854,911$; Coronavirus Resource Center, 2020).

Despite the findings, the study has some limitations. First, the four variables of dysfunctional COVID-19 grief, anxiety, depression, and suicidal ideation were assessed with self-report measures that may be influenced by social desirability, recall, or other biases. Therefore, it would have been preferable for these assessments to be conducted by a clinical psychologist; however, this was not the aim of the study and should be investigated in future studies. Second, the participants were selected by convenience sampling, so they were not fully representative of the general population of Peru, making it impossible to generalize the results (Markus \& Borsboom, 2013). Thus, it is important to use nationally representative samples in future studies to confirm the findings reported here. Third, the majority of participants were female and, therefore, it was not possible to test for gender differences. Fourth, due to the online nature of the data collection process, the study was limited to only those with internet access, which may have resulted in selection bias. However, due to mandatory social isolation and social interaction restrictions, online surveys have been the only viable option for collecting information during the pandemic (Abbady et al., 2021). Fifth, a gender imbalance was observed, where more than twice as many participants were female. Because of this imbalance, we recommend that future studies seek to have more homogeneous samples. Sixth, as the study had a cross-sectional design, the associations between grief, anxiety, depression, and suicidal ideation did not provide information on causality. Due to the daily increase in the number of infections and deaths due to the pandemic, future studies should include longitudinal designs to assess causality between variables and 
variations in these associations over time. This is important, as assessing dysfunctional grief from the COVID-19 pandemic over time would allow for the development of preventive public health practices (Alyami et al., 2020). Seventh, we did not examine the stability of PGS scores over a period of time, so future test-retest reliability estimates should be incorporated. Finally, the sensitivity and specificity of the Spanish version of the PGS were not examined. Therefore, future research should include an analysis of the diagnostic properties of the measure.

\section{Conclusion}

Despite these limitations, the findings of this study are significant because they confirm the evidence of validity and reliability of the PGS in its Spanish version, using traditional and modern methods. Specifically, the unidimensional model of the PGS was found to have good fit and reliability; furthermore, convergent validity was demonstrated from the relationships between dysfunctional grief, anxiety symptoms, depression, and suicidal ideation. Finally, a greater presence of dysfunctional grief is needed to answer the higher response categories of the PGS. Furthermore, although the sample of participants was not representative, the number of participants is higher than some recommended criteria for instrumental studies, such as the proportion of 20 participants for each item (Gorsuch, 2015). In this sense, the Spanish version of the PGS has potential as a brief measure of dysfunctional grief related to COVID-19 and that may be useful in large-scale epidemiological studies, as well as for the detection of the presence and magnitude of dysfunctional grief related to COVID-19 and treatment in the Peruvian population. Thus, the PGS is expected to generate important new empirical findings on the nature of dysfunctional grief from the COVID-19 pandemic in particular and in other future pandemics. However, future research is needed in various Spanish-speaking countries and over a long period of time to understand more about the usefulness of the PGS in Spanish, with the objective of developing prevention or intervention programs in at-risk groups, such as those who have lost a loved one to the current pandemic of COVID-19.

Author Contribution All authors contributed to the study conception and design. Material preparation and data collection were performed by Tomás Caycho-Rodríguez, Andrea Vivanco-Vidal, Daniela SaroliAranibar, Carlos Carbajal León, Walter Arias Gallego, and Michael White. Data analysis was performed by Lindsey W Vilca. Sherman A. Lee wrote all the modifications suggested in the last revision. In addition, he reviewed the entire text and made editorial modifications to the document. The first draft of the manuscript was written by Tomás Caycho-Rodríguez and all authors commented on previous versions of the manuscript. All authors read and approved the final manuscript.

Funding This research was funded by Universidad Privada del Norte.

Data Availability The database is available with a request to the corresponding author.

\section{Declarations}

Ethics Approval This study was performed in line with the principles of the Declaration of Helsinki. Approval was granted by the Ethics Committee of Universidad Privada del Norte (UPN/DNID/20203001). 
Consent to Participate Informed consent was obtained from all individual participants included in the study.

Consent for Publication Does not apply.

Competing Interests The authors declare no competing interests.

\section{References}

Abbady, A. S., El-Gilany, A. H., El-Dabee, F. A., Elsadek, A. M., ElWasify, M., \& Elwasify, M. (2021). Psychometric characteristics of the of COVID Stress Scales-Arabic version (CSS-Arabic) in Egyptian and Saudi university students. Middle East Current Psychiatry, 28(1), 1-9. https://doi.org/10. 1186/s43045-021-00095-8

Adler, M., \& Brodin, U. (2011). An IRT validation of the affective self rating scale. Nordic Journal of Psychiatry, 65(6), 396-402. https://doi.org/10.3109/08039488.2011.577187

Alyami, M., Henning, M., Krägeloh, C. U., Alyami, H. (2020). Psychometric evaluation of the Arabic version of the Fear of COVID-19 Scale. International Journal of Mental Health and Aaddiction 1-14 https://doi.org/10.1007/s11469-020-00316-X

Atkinson, R., \& Flint, J. (2004). Snowball sampling. In M. S. Lewis-Beck, A. Bryman, \& T. Futing Liao (Eds.), The sage encyclopaedia of social science research methods (Vol. 1, pp. 1043-1044). Sage.

Ato, M., López-García, J. J., \& Benavente, A. (2013). Un sistema de clasificación de los diseños de investigación en psicología. Anales de Psicología, 29(3), 1038-1059. https://doi.org/10.6018/analesps. 29.3.178511

Atwoli, L., Stein, D. J., King, A., Petukhova, M., Aguilar-Gaxiola, S., Alonso, J., ... Kessler, R. C. (2017). Posttraumatic stress disorder associated with unexpected death of a loved one: Crossnational findings from the World Mental Health Surveys. Journal of Depression and Anxiety, 34(4), 315-326. https://doi.org/10.1002/da.22579

Baltar, F., \& Brunet, I. (2012). Social research 2.0: virtual snowball sampling method using Facebook. Internet Research, 22(1), 57-74. https://doi.org/10.1108/10662241211199960

Beaton, D. E., Bombardier, C., Guillemin, F., \& Ferraz, M. B. (2000). Guidelines for the process of crosscultural adaptation of self-report measures. Spine, 25(24), 3186-3191.

Bertuccio, R. F., \& Runion, M. C. (2020). Considering grief in mental health outcomes of COVID-19. Psychological Trauma: Theory, Research, Practice, and Policy, 12(S1), S87-S89. https://doi.org/ $10.1037 / \operatorname{tra} 0000723$

Boelen, P. A., \& Smid, G. E. (2017). Disturbed grief: Prolonged grief disorder and persistent complex bereavement disorder. BMJ, 357, j2016. https://doi.org/10.1136/bmj.j2016

Boelen, P. A., \& van den Bout, J. (2005). Complicated grief, depression, and anxiety as distinct postloss syndromes: A confirmatory factor analysis study. American Journal of Psychiatry, 162(11), 21752177. https://doi.org/10.1176/appi.ajp.162.11.2175

Breen, L. J., Lee, S. A., \& Neimeyer, R. A. (2021). Psychological risk factors of functional impairment after COVID-19 deaths. Journal of Pain and Symptom Management, 61(4), e1-e4. https://doi.org/ 10.1016/j.jpainsymman.2021.01.006

Brown, T. A. (2015). Confirmatory factor analysis for applied research, Second Edition. Guilford Publications. https://books.google.com.pe/books?id=tTL2BQAAQBAJ

Carr, D., Boerner, K., \& Moorman, S. (2020). Bereavement in the time of coronavirus: Unprecedented challenges demand novel interventions. Journal of Aging \& Social Policy, 32(4-5), 425-431. https://doi.org/10.1080/08959420.2020.1764320

Caycho-Rodríguez, T., Barboza-Palomino, M., Ventura-León, J., Carbajal-León, C., Noé-Grijalva, M., Gallegos, M., ... Vivanco-Vidal, A. (2020). Traducción al español y validación de una medida breve de ansiedad por la COVID-19 en estudiantes de ciencias de la salud. Ansiedad y Estrés, 26 (2-3), 174180 https://doi.org/10.1016/j.anyes.2020.08.001

Caycho-Rodríguez, T., Tomás, J. M., Barboza-Palomino, M., Ventura-León, J., Gallegos, M., ReyesBossio, M., Vilca, L. W. (2021a) Assessment of fear of COVID-19 in older adults: Validation of 
the fear of COVID-19 scale. International Journal of Mental Health and Addiction 1-15 https:// doi.org/10.1007/s11469-020-00438-2

Caycho-Rodríguez, T., Tomás, J. M., Ventura-León, J., Sancho, P., Cabrera-Orosco, I., \& Barboza-Palomino, M. (2021b). Medición de la voluntad de vivir en adultos mayores: Adaptación transcultural, validez y confiabilidad de la Will-to-Live Scale. Enfermería Clínica, 31(1), 4-11. https://doi.org/ 10.1016/j.enfcli.2020.06.078

Caycho-Rodríguez, T., Vilca, L. W., Carbajal-León, C., Heredia-Mongrut, J., Gallegos, M., Portillo, N., ... Barboza-Palomino, M. (2021c) Obsession with Covid-19 in Peruvian police and armed forces: Validation of the obsession with Covid-19 Scale in Spanish using SEM and IRT models. Death Studies 1-11 https://doi.org/10.1080/07481187.2021.1900453

Chávez-Flores, Y., Hidalgo-Rasmussen, C., \& González-Betanzos, F. (2018). Adaptación transcultural del cuestionario ISSIQ-A para evaluar Impulsividad, Autolesión No Suicida e Ideación Suicida en adolescentes mexicanos. Terapia Psicológica, 36(2), 91-99. https://doi.org/10.4067/S0718-48082 018000200091

Cohen, J. (1992). A power primer. Psychological Bulletin, 112(1), 155-159. https://doi.org/10.1037/ 0033-2909.112.1.155

Cooper, A., \& Petrides, K. V. (2010). A psychometric analysis of the Trait Emotional Intelligence Questionnaire-Short Form (TEIQue-SF) using item response theory. Journal of Personality Assessment, 92(5), 449-457. https://doi.org/10.1080/00223891.2010.497426

Coronavirus Resource Center (2020). COVID-19 dashboard by the Center for Systems Science and Engineering (CSSE) at Johns Hopkins University (JHU). https://coronavirus.jhu.edu/map.html

Crocker, L. \& Algina, J. (1986). Introduction to classical and modern test theory. Fort Worth: Holt, Rinehart and Winston

Cronbach, L. J. (1951). Coefficient alpha and the internal structure of tests. Psychometrika, 16(3), 297334. https://doi.org/10.1007/BF02310555

Czeisler, M. É., Lane, R. I., Petrosky, E., Wiley, J. F., Christensen, A., Njai, R., ... \& Rajaratnam, S. M. (2020). Mental health, substance use, and suicidal ideation during the COVID-19 pandemic-United States, June 24-30, 2020. Morbidity and Mortality Weekly Report, 69(32), 1049-1057. https://doi. org/10.15585/mmwr.mm6932a1

Dillen, L., Fontaine, J. R., \& Verhofstadt-Denève, L. (2009). Confirming the distinctiveness of complicated grief from depression and anxiety among adolescents. Death Studies, 33(5), 437-461. https:// doi.org/10.1080/07481180902805673

Dominguez-Lara, S. (2018). Propuesta de puntos de corte para cargas factoriales: Una perspectiva de fiabilidad de constructo. Enfermería Clínica, 28(6), 401-402. https://doi.org/10.1016/j.enfcli.2018. 06.002

Dominguez-Lara, S. (2019). Correlación entre residuales en análisis factorial confirmatorio: una breve guía para su uso e interpretación. Interacciones, 5(3), e207. https://doi.org/10.24016/2019.v5n3. 207

Eisma, M. C., \& Tamminga, A. (2020). Grief before and during the COVID-19 pandemic: Multiple group comparisons. Journal of Pain and Symptom Management, 60(6), e1-e4. https://doi.org/10. 1016/j.jpainsymman.2020.10.004

Eisma, M. C., Tamminga, A., Smid, G. E., \& Boelen, P. A. (2021). Acute grief after deaths due to COVID-19, natural causes and unnatural causes: An empirical comparison. Journal of Affective Disorders, 278, 54-56. https://doi.org/10.1016/j.jad.2020.09.049

El-Den, S., Chen, T. F., Gan, Y. L., Wong, E., \& O'Reilly, C. L. (2018). The psychometric properties of depression screening tools in primary healthcare settings: A systematic review. Journal of Affective Disorders, 225, 503-522. https://doi.org/10.1016/j.jad.2017.08.060

Evren, C., Evren, B., Dalbudak, E., Topcu, M., Kutlu, N. (2021). Measuring dysfunctional grief due to a COVID-19 loss: A Turkish validation study of the Pandemic Grief Scale. Death Studies 1-9 https://doi.org/10.1080/07481187.2021.1897179

Finney, S. J. y DiStefano, C. (2006). Non-normal and categorical data in structural equation modeling. En G. R. Hancock y R. O. Mueller (Eds.), Structural equation modeling. A second course (pp. 269-314). Greenwich, CT: Information Age Publishing.

Fitzpatrick, K. M., Harris, C., \& Drawve, G. (2020). Fear of COVID-19 and the mental health consequences in America. Psychological Trauma: Theory, Research, Practice and Policy, 12(S1), S17S21. https://doi.org/10.1037/tra0000924 
Fornell, C., \& Larcker, D. F. (1981). Evaluating structural equation models with unobservable variables and measurement error. Journal of marketing research, 18(1), 39-50. https://doi.org/10.1177/ 002224378101800104

Fujisawa, D., Miyashita, M., Nakajima, S., Ito, M., Kato, M., \& Kim, Y. (2010). Prevalence and determinants of complicated grief in general population. Journal of Affective Disorders, 127(1-3), 352358. https://doi.org/10.1016/j.jad.2010.06.008

Gesi, C., Carmassi, C., Cerveri, G., Carpita, B., Cremone, I. M., \& Dell'Osso, L. (2020). Complicated grief: What to expect after the coronavirus pandemic. Frontiers in Psychiatry, 11, 489. https://doi. org/10.3389/fpsyt.2020.00489

Gorsuch, R. L. (2015). The replication and invariance of factors. Factor Analysis: Classical Edition. Taylor \& Francis, New York

Hambleton, R. K., van der Linden, W. J., \& Wells, C. S. (2010). IRT models for the analysis of polytomously scored data: Brief and selected history of model building advances. In M. L. Nering \& R. Ostini (Eds.), Handbook of polytomous item response models (pp. 21-42). Routledge.

Hambleton, R. K., Swaminathan, H., y Rogers, J. (1991).Fundamentals of item response theory. Sage

Hamid, W., \& Jahangir, M. S. (2020). Dying, death and mourning amid COVID-19 pandemic in Kashmir: A qualitative study. OMEGA-Journal of Death and Dying. https://doi.org/10.1177/00302 22820953708

Hardy-Bougere, M. (2008). Cultural manifestations of grief and bereavement: A clinical perspective. Journal of Cultural Diversity, 15(2), 66-69.

Hill, R. M., Kaplow, J. B., Oosterhoff, B., \& Layne, C. M. (2019). Understanding grief reactions, thwarted belongingness, and suicide ideation in bereaved adolescents: Toward a unifying theory. Journal of Clinical Psychology, 75(4), 780-793. https://doi.org/10.1002/jclp.22731

Ito, M., Nakajima, S., Fujisawa, D., Miyashita, M., Kim, Y., Shear, M. K., ... Wall, M. M. (2012) Brief measure for screening complicated grief: Reliability and discriminant validity. PLoS ONE, 7(2): e31209 https://doi.org/10.1371/journal.pone.0031209

Johns, L., Blackburn, P., \& McAuliffe, D. (2020). COVID-19, prolonged grief disorder and the role of social work. International Social Work, 63(5), 660-664. https://doi.org/10.1177/0020872820 941032

Kenny, D. A., Kaniskan, B., \& McCoach, D. B. (2015). The performance of RMSEA in models with small degrees of freedom. Sociological Methods \& Research, 44(3), 486-507. https://doi.org/10. $1177 / 0049124114543236$

Kline, R. B. (2015). Principles and practice of structural equation modeling (4th ed.). The Guilford Press.

Kokou-Kpolou, C. K., Fernández-Alcántara, M., \& Cénat, J. M. (2020). Prolonged grief related to COVID-19 deaths: Do we have to fear a steep rise in traumatic and disenfranchised griefs? Psychological Trauma: Theory, Research, Practice, and Policy, 12(S1), S94-S95. https://doi.org/10. 1037/tra0000798

Kroenke, K., Spitzer, R. L., \& Williams, J. B. (2003). The Patient Health Questionnaire-2: Validity of a two-item depression screener. Medical Care, 41(11), 1284-1292.

Kroenke, K., Spitzer, R. L., Williams, J. B., Monahan, P. O., \& Löwe, B. (2007). Anxiety disorders in primary care: Prevalence, impairment, comorbidity, and detection. Annals of Internal Medicine, 146(5), 317-325. https://doi.org/10.7326/0003-4819-146-5-200703060-00004

Leaune, E., Samuel, M., Oh, H., Poulet, E., \& Brunelin, J. (2020). Suicidal behaviors and ideation during emerging viral disease outbreaks before the COVID-19 pandemic: A systematic rapid review. Preventive Medicine, 141, 106264. https://doi.org/10.1016/j.ypmed.2020.106264

Lee, S. A. (2015). The persistent complex bereavement inventory: A measure based on the DSM-5. Death Studies, 39(7), 399-410. https://doi.org/10.1080/07481187.2015.1029144

Lee, S. A., Neimeyer, R. A. (2020). Pandemic Grief Scale: A screening tool for dysfunctional grief due to a COVID-19 loss.Death Studies, 1-11 https://doi.org/10.1080/07481187.2020.1853885

Lenferink, L. I., \& Eisma, M. C. (2018). 37,650 ways to have "persistent complex bereavement disorder" yet only 48 ways to have "prolonged grief disorder." Psychiatry Research, 261, 88-89. https://doi. org/10.1016/j.psychres.2017.12.050

Lenferink, L. I., Nickerson, A., de Keijser, J., Smid, G. E., \& Boelen, P. A. (2020). Trajectories of grief, depression, and posttraumatic stress in disaster-bereaved people. Depression and Anxiety, 37(1), 35-44. https://doi.org/10.1002/da.22850

Li, T., Saklofske, D. H., Bowden, S. C., Yan, G., \& Fung, T. S. (2012). The measurement invariance of the Wong and Law Emotional Intelligence Scale (WLEIS) across three Chinese university student 
groups from Canada and China. Journal of Psychoeducational Assessment, 30(4), 439-452. https:// doi.org/10.1177/0734282912449449

Lichtenthal, W. G., Cruess, D. G., \& Prigerson, H. G. (2004). A case for establishing complicated grief as a distinct mental disorder in DSM-V. Clinical Psychology Review, 24(6), 637-662. https://doi.org/ 10.1016/j.cpr.2004.07.002

Lord, F. M. (1982). Standard error of an equating by item response theory. Applied Psychological Measurement, 6(4), 463-472. https://doi.org/10.1177/014662168200600407

Löwe, B., Kroenke, K., \& Gräfe, K. (2005). Detecting and monitoring depression with a two-item questionnaire (PHQ-2). Journal of Psychosomatic Research, 58(2), 163-171. https://doi.org/10.1016/j. jpsychores.2004.09.006

Markus, K. A., \& Borsboom, D. (2013). Frontiers of test validity theory: Measurement, causation, and meaning. Routledge.

Marques, L., Bui, E., LeBlanc, N., Porter, E., Robinaugh, D., Dryman, M. T., ... Simon, N. (2013) Complicated grief symptoms in anxiety disorders: Prevalence and associated impairment Depression and Anxiety, 30 (12), 1211-1216 https://doi.org/10.1002/da.22093

McDonald, R. P. (1999). Test theory: A unified treatment. Taylor \& Francis.

McNeish, D. (2018). Thanks coefficient alpha, we'll take it from here. Psychological Methods, 23(3), 412-433. https://doi.org/10.1037/met0000144

Milfont, T. L., \& Fischer, R. (2010). Testing measurement invariance across groups: Applications in cross cultural research. International Journal of Psychological Research, 3(1), 111-130. https://doi.org/ $10.21500 / 20112084.857$

Ministerio de Salud (2021). Sala situacional Covid-19 Perú. https://covid19.minsa.gob.pe/sala_situa cional.asp

Molina, N., Viola, M., Rogers, M., Ouyang, D., Gang, J., Derry, H., \& Prigerson, H. G. (2019). Suicidal ideation in bereavement: A systematic review. Behavioral Sciences, 9(5), 53. https://doi.org/10. 3390/bs9050053

Mortazavi, S. S., Assari, S., Alimohamadi, A., Rafiee, M., \& Shati, M. (2020). Fear, loss, social isolation, and incomplete grief due to COVID-19: a recipe for a psychiatric pandemic. Basic and Clinical Neuroscience, 11(2), 225-232. https://doi.org/10.32598/bcn.11.covid19.2549.1

Nicholson, P., Griffin, P., Gillis, S., Wu, M., \& Dunning, T. (2013). Measuring nursing competencies in the operating theatre: Instrument development and psychometric analysis using Item Response Theory. Nurse Education Today, 33(9), 1088-1093. https://doi.org/10.1016/j.nedt.2012.04.008

Parry, J. K., \& Ryan, A. S. (Eds.). (1996). A cross-cultural look at death, dying, and religion. Nelson-Hall.

Pearce, C., Honey, J.R., Lovick, R., Creamer, N. Z., Henry, C., Langford, A., ... Barclay, S. (2021). 'A silent epidemic of grief': A survey of bereavement care provision in the UK and Ireland during the COVID-19 pandemic. British Medical Journal Open, 11(3), e046872 https://doi.org/10.1136/ bmjopen-2020-046872

Petrillo, J., Cano, S. J., McLeod, L. D., \& Coon, C. D. (2015). Using classical test theory, item response theory, and Rasch measurement theory to evaluate patient-reported outcome measures: A comparison of worked examples. Value in Health, 18(1), 25-34. https://doi.org/10.1016/j.jval.2014.10.005

Powell, K. A., \& Matthys, A. (2013). Effects of suicide on siblings: Uncertainty and the grief process. Journal of Family Communication, 13(4), 321-339. https://doi.org/10.1080/15267431.2013. 823431

Prigerson, H. G., Horowitz, M. J., Jacobs, S. C., Parkes, C. M., Aslan, M., Goodkin, K., ... Maciejewski, P. K. (2009). Prolonged grief disorder: Psychometric validation of criteria proposed for DSM-V and ICD-11. PLoS Medicine, 6(8), e1000121 https://doi.org/10.1371/journal.pmed.1000121

$\mathrm{R}$ Core Team. (2019). A language and environment for statistical computing ( $R$ version 3.6.1). R Foundation for Statistical Computing. http://www.r-project.org/

Rauschenberg, C., Schick, A., Hirjak, D., Seidler A., Paetzold, I., Apfelbacher, C., ...Reininghaus, U. (2021) Evidence synthesis of digital interventions to mitigate the negative impact of the COVID19 pandemic on public mental health: Rapid meta-review. Journal of Medical Internet Research, 23(3), e23365. https://doi.org/10.2196/23365

Raykov, T., \& Hancock, G. R. (2005). Examining change in maximal reliability for multiple-component measuring instruments. British Journal of Mathematical and Statistical Psychology, 58(1), 65-82. https://doi.org/10.1348/000711005X38753

Revelle, W., \& Condon, D. M. (2019). Reliability from $\alpha$ to $\omega$ : A tutorial. Psychological Assessment, 31(12), 1395-1411. https://doi.org/10.1037/pas0000754 
Rizopoulos, D. (2006). 1tm: An R package for latent variable modelling and item response theory analyses. Journal of Statistical Software, 17(5), 1-25. https://doi.org/10.18637/jss.v017.i05

Rosenblatt, P. C. (2001). A social constructionist perspective on cultural differences in grief. In M. S. Stroebe, R. O. Hansson, W. Stroebe, \& H. Schut (Eds.), Handbook of bereavement research: Consequences, coping, and care (p. 285-300). American Psychological Association. https://doi.org/10. 1037/10436-012

Rosseel, Y. (2012). lavaan: An R package for structural equation modeling. Journal of Statistical Software, 48(2), 1-36. https://doi.org/10.18637/jss.v048.i02

RStudio Team. (2018). RStudio: Integrated development environment for R. RStudio, Inc. http://www. rstudio.com/

Samejima, F. (1997). Graded response model. In W. J. Van der Linden \& R. K. Hambleton (Eds.), Handbook of modern Item Response Theory (pp. 85-100). Springer.

Satici, B., Gocet-Tekin, E., Deniz, M. E., Satici, S. A; (2020). Adaptation of the fear of COVID-19 scale: Its association with psychological distress and life satisfaction in Turkey. International Journal of Mental Health and Addiction 1-9 https://doi.org/10.1007/s11469-020-00294-0

Schumacker, R. E., \& Lomax, R. G. (2015). A Beginner's Guide to Structural Equation Modeling: Fourth Edition (4th ed.). Routledge.

Shear, M. K., \& Skritskaya, N. A. (2012). Bereavement and anxiety. Current Psychiatry Reports, 14(3), 169-175. https://doi.org/10.1007/s11920-012-0270-2

Shi, L., Que, J. Y., Lu, Z. A., Gong, Y. M., Liu, L., Wang, Y. H., ... Lu, L. (2021). Prevalence and correlates of suicidal ideation among the general population in China during the COVID-19 pandemic.European Psychiatry, 64(1), e18. https://doi.org/10.1192/j.eurpsy.2021.5

Simon, N. M., Saxe, G. N., \& Marmar, C. R. (2020). Mental health disorders related to COVID-19related deaths. JAMA, 324(15), 1493-1494. https://doi.org/10.1001/jama.2020.19632

Skalski, S., Konaszewski, K., Dobrakowski, P., Surzykiewicz, J., \& Lee, S. A. (2021). Pandemic grief in Poland: Adaptation of a measure and its relationship with social support and resilience. Current Psychology. https://doi.org/10.1007/s12144-021-01731-6

Soper, D.S. (2021). A-priori sample size calculator for structural equation models [Software]. Retrieved from http://www.danielsoper.com/statcalc.

Stroebe, M., Schut, H., \& Stroebe, W. (2007). Health outcomes of bereavement. The Lancet, 370(9603), 1960-1973. https://doi.org/10.1016/S0140-6736(07)61816-9

Taasoobshiraz, G., \& Wang, S. (2016). the performance of the SRMR, RMSEA, CFI and TLI: An examination of sample size, path size, and degrees of freedom. Journal of Applied Quantitative Methods, 11(3), 31-39.

Tasnim, R., Islam, M. S., Sujan, M. S. H., Sikder, M. T., \& Potenza, M. N. (2020). Suicidal ideation among Bangladeshi university students early during the COVID-19 pandemic: Prevalence estimates and correlates. Children and Youth Services Review, 119, 105703. https://doi.org/10.1016/j. childyouth.2020.105703

Terwee, C. B., Bot, S. D. M., de Boer, M. R., van der Windt, D. A. W. M., Knol, D. L., Dekker, J., Bouter, L. M., \& de Vet, H. C. W. (2007). Quality criteria were proposed for measurement properties of health status questionnaires. Journal of Clinical Epidemiology, 60(1), 34-42. https://doi.org/ 10.1016/j.jclinepi.2006.03.012

Twenge, J. M., \& Joiner, T. E. (2020). Mental distress among US adults during the COVID-19 pandemic. Journal of Clinical Psychology, 76(12), 2170-2182. https://doi.org/10.1002/jclp.23064

Van Orden, K. A., Witte, T. K., Cukrowicz, K. C., Braithwaite, S. R., Selby, E. A., \& Joiner, T. E., Jr. (2010). The interpersonal theory of suicide. Psychological Review, 117(2), 575. https://doi.org/10.1037/a0018697

Williamson, E. J., Walker, A. J., Bhaskaran, K., Bacon, S., Bates, C., Morton, C. E, ... Goldacre, B. (2020) Factors associated with COVID-19-related death using OpenSAFELY. Nature, 584 (7821), 430 436. https://doi.org/10.1038/s41586-020-2521-4

Yang, Y., \& Green, S. B. (2010). A note on structural equation modeling estimates of reliability. Structural Equation Modeling, 17(1), 66-81. https://doi.org/10.1080/10705510903438963

Zhai, Y., \& Du, X. (2020). Loss and grief amidst COVID-19: A path to adaptation and resilience. Brain, Behavior, and Immunity, 87, 80-81. https://doi.org/10.1016/j.bbi.2020.04.053

Zisook, S., Iglewicz, A., Avanzino, J., Maglione, J., Glorioso, D., Zetumer, S., ... Shear, M. K. (2014). Bereavement: Course, consequences, and care. Current Psychiatry Reports, 16(10), 482 https://doi. org/10.1007/s11920-014-0482-8

Zisook, S., Schneider, D., \& Shuchter, S. R. (1990). Anxiety and bereavement. Psychiatric Medicine, $8(2), 83-96$. 